\title{
The potential for land sparing to offset greenhouse gas emissions from agriculture
}

Anthony Lamb ${ }^{1}$, Rhys Green ${ }^{1,2}$, Ian Bateman ${ }^{3}$, Mark Broadmeadow ${ }^{4}$, Toby Bruce ${ }^{5}$, Jennifer Burney $^{6}$, Pete Carey ${ }^{7}$, David Chadwick ${ }^{8}$, Ellie Crane ${ }^{2}$, Rob Field ${ }^{2}$, Keith Goulding ${ }^{5}$, Howard Griffiths $^{7}$, Astley Hastings ${ }^{9}$, Tim Kasoar ${ }^{1}$, Daniel Kindred ${ }^{10}$, Ben Phalan ${ }^{1}$, John Pickett ${ }^{5}$, Pete Smith $^{9}$, Eileen Wall ${ }^{11}$, Erasmus K. H. J. zu Ermgassen ${ }^{1} \&$ Andrew Balmford ${ }^{1}$

${ }^{1}$ Department of Zoology, University of Cambridge, Downing St, Cambridge CB2 3EJ, UK

${ }^{2}$ RSPB Centre for Conservation Science, Royal Society for the Protection of Birds, The Lodge, Sandy SG19 2DL, UK

${ }^{3}$ Centre for Social and Economic Research on the Global Environment (CSERGE), Department of Politics, The University of Exeter, Mail Room, The Old Library, Prince of Wales Road, Exeter EX4 4SB, UK

${ }^{4}$ Forestry Commission, Alice Holt, Farnham, Surrey GU10 4LH, UK

${ }^{5}$ Rothamsted Research, Harpenden, Herts AL5 2JQ, UK

${ }^{6}$ School of Global Policy and Strategy, University of California, San Diego, 9500 Gilman Drive, La Jolla CA 92093-0519, USA

${ }^{7}$ Department of Plant Sciences, University of Cambridge, Downing Street, Cambridge CB2 3EA, UK

${ }^{8}$ School of Environment, Natural Resources and Geography, Bangor University, Deiniol Rd., Bangor, Gwynedd LL57 2UW, UK

${ }^{9}$ Scottish Food Security Alliance-Crops, ClimateXChange \& Institute of Biological and Environmental Science, University of Aberdeen, 23 St Machar Drive, Aberdeen AB24 3UU, UK

${ }^{10}$ ADAS UK Ltd, Boxworth, Cambridge CB23 4NN, UK

${ }^{11}$ ClimateXChange \& Scotland's Rural College (SRUC), West Mains Road, Edinburgh EH9 3JG, UK 
Greenhouse gas emissions from global agriculture are increasing at around $1 \%$ per annum, yet substantial cuts in emissions are needed across all sectors ${ }^{1}$. The challenge of reducing agricultural emissions is particularly acute, because the reductions achievable by changing farming practices are limited ${ }^{2,3}$ and are hampered by rapidly rising food demand $^{4,5}$. Here we assess the technical mitigation potential offered by land sparing increasing agricultural yields, reducing farmland area and actively restoring natural habitats on the land spared ${ }^{6}$. Restored habitats can sequester carbon and can offset emissions from agriculture. Using the United Kingdom as an example, we estimate net emissions in $\mathbf{2 0 5 0}$ under a range of future agricultural scenarios. We find that a landsparing strategy has the technical potential to achieve significant reductions in net emissions from agriculture and land-use change. Coupling land sparing with demandside strategies to reduce meat consumption and food waste can further increase the technical mitigation potential, however economic and implementation considerations might limit the degree to which this technical potential could be realised in practice.

We projected the mitigation potential of land sparing in the United Kingdom with reference to its binding commitment to reduce emissions by $80 \%$ by 2050 (relative to 1990 levels) ${ }^{7}$. We began by identifying a technically plausible range in the future yields of all major crop and livestock commodities produced in the UK, based on historic trends and future potential. We define yields as the annual tonnage of production per hectare for crops and the feed conversion ratio (feed consumed per kilogram of production) for livestock. Future yields could vary across a wide range, driven by a number of biophysical, technical and socioeconomic factors ${ }^{8-11}$. We assessed the likely bounds of this range based on an assessment of technical potential and reflect this in our projections, which span yield declines through to sustained long-term growth averaging $1.3 \%$ per annum across all commodities 
(Table 1; Supplementary Fig. 1; Supplementary Discussion). For the avoidance of doubt, we do not equate our lower yielding scenarios with 'land sharing'.

We next projected emissions attributable to UK agricultural production out to 2050, quantifying all sources of emissions that would be affected by a land-sparing strategy. We therefore quantified not only emissions reported under 'Agriculture' in the UK's greenhouse gas inventory ${ }^{12}$, but also emissions related to agriculture but reported in other sectors (e.g. farm energy use, agro-chemical production and land-use change), and emissions arising overseas due to imported feed for livestock (see Supplementary Table 1 for all emissions sources quantified). Our projections assumed that agricultural production increases from present levels in proportion to projected demand growth (Supplementary Table 2). In certain scenarios, projected UK farming capacity does not keep pace with demand growth. In such cases we assumed an increase in imports and accounted for the overseas emissions associated with those imports.

Next we formulated a land-sparing strategy. As yields increase, the area of farmland required for a given level of production declines, allowing land to be spared. Our definition of land sparing includes the active restoration of habitats on spared land and our main scenario assumed the restoration of wet peatland (on spared organic soils) and native broadleaved forest (on spared mineral soils) (Supplementary Table 3). We quantified the greenhouse gas fluxes from the soils and biomass of these habitats, drawing on the UK's carbon accounting methodology ${ }^{12}$ and IPCC guidelines ${ }^{13}$.

The fourth step in our calculation was to combine emissions from farming with emissions from land-use change and compare projected net emissions in 2050 with the equivalent baseline emissions in 1990 (Supplementary Table 1). We find that there is significant scope to mitigate emissions through land sparing (Fig. 1a). At the lower-bound of our yield 
projections, emissions are projected to increase relative to current levels, reflecting increased agricultural production in 2050. In contrast, if yield growth towards the upper-bound of our projections could be realised, emissions from farming are lower (due primarily to more efficient livestock production; Fig. 1b) and the active restoration of habitats on spared land leads to significant carbon sequestration. The upper-bound of technical potential approaches a decline in net emissions of $80 \%$ relative to the 1990 baseline (the UK's greenhouse gas reduction target), though economic and implementation considerations are likely to limit the degree to which that technical potential could be realised in practice.

To explore the scope for combining emissions reduction strategies, we next assessed two promising demand-side measures ${ }^{14}$ implemented alongside land sparing. We quantified the effect of replacing some animal products in the diet with vegetarian substitutes (Fig. 2a) and the effect of reducing food waste (Fig. 2b), in both cases maintaining the land-sparing strategy based on active restoration of natural habitats. Reducing meat consumption appears to offer greater mitigation potential than reducing food waste, but more importantly, our results highlight the benefits of combining measures. For example, coupling even moderate yield growth with land sparing and reductions in meat consumption has the technical potential to surpass an $80 \%$ reduction in net emissions (Fig. 2a).

Last, we quantified the technical mitigation potential of a number of possible alternative uses of spared land: allowing natural regeneration (a low-cost option); establishing faster growing coniferous rather than native broadleaved forest; and growing bioenergy crops (which can mitigate emissions by displacing fossil fuels) (Fig. 3). We find that actively restoring forest increases the rate of carbon sequestration compared with natural regeneration, and coniferous woodland sequesters more carbon than native broadleaved woodland. Our results suggest that the mitigation potential of oilseed rape for biodiesel is negligible, and the potential of 
Miscanthus and short-rotation coppice depends strongly on the fossil fuel being displaced, only outperforming natural regeneration if displacing coal.

The scenarios we have assessed indicate that land sparing offers the technical potential for substantial mitigation. The degree to which that technical potential could be realised in practice depends on a number of factors. Our upper-bound scenario entails large, ongoing and environmentally sustainable increases in farm yields. A key issue, therefore, is identifying the mechanisms that could contribute to this outcome. Rates of yield growth in key crops have declined in recent years (Supplementary Fig. 1). Competing hypotheses explain the decline (see Supplementary Discussion). The first argues that insurmountable biophysical limits are constraining yield growth ${ }^{9}$, a situation that might be compounded by climate change ${ }^{15}$, and this outcome is reflected at the lower-bound of our yield projections. The second hypothesis argues that yields are well within biophysical limits, but that regulatory and market conditions and declines in research and development have reduced incentives to invest in yield growth ${ }^{9-11}$. These factors are controllable so under the second hypothesis there is significant scope for future yield growth. Our results highlight the technical potential for substantial mitigation if these barriers to yield growth can be overcome as part of a landsparing strategy.

A large proportion of projected upper-bound mitigation arises due to assumed growth in livestock productivity (Fig. 1b). Our upper-bound livestock productivity gains (Table 1) assume that technological advancements lead to continued genetic gains through breeding, coupled with improved livestock health and nutrition. These gains contribute approximately half of the upper-bound mitigation in 2050 (Fig. 1b) but might be untenable in practice on economic, animal welfare or technical grounds and we note that other studies predict much lower future livestock productivity growth in Europe (see Supplementary Discussion). Encouragingly however, if even moderate productivity gains could be realised and coupled 
with policies that encourage reduced meat diets, the technical mitigation potential is pronounced (Fig. 2a). Altering consumer dietary behaviour is challenging, but aided by expected health benefits ${ }^{16}$, a number of policy options are available. Taxes and subsidies in particular are demonstrably effective at driving diet change ${ }^{17}$ (see Supplementary Discussion).

We have assessed the technical potential but not the economic feasibility of a land-sparing strategy. UK land use and production decisions are affected by global food prices ${ }^{18}$, so realising land sparing in practice requires policies that couple yield increases with habitat restoration on spared land. In the UK, the obvious mechanism to effect this is via reform of the EU's Common Agricultural Policy ${ }^{18}$. Any mechanism would need to be carefully designed so as to function given the UK's role in the world food economy. Leakage and rebound effects might reduce the mitigation achieved, and increases in global food prices might compromise a land-sparing strategy by creating an incentive to farm, rather than spare, land ${ }^{19,20}$. Integrating our approach with models linking the global agricultural economy, land use and the changing climate ${ }^{21}$ would enable a broader assessment of land sparing in the context of global markets, emissions and food security. Economic considerations will also inform the most appropriate use of spared land. Natural regeneration represents a low-cost option, so any incremental mitigation benefits from managed forestry or bioenergy should be balanced against the additional management costs under these options. Similarly, displacing fossil fuels using bioenergy might not be the best overall strategy: if the UK energy sector could reduce emissions by $80 \%$ using other clean energy sources (thereby limiting the mitigation achievable using bioenergy), using spared land to grow forests rather than bioenergy crops would result in greater overall mitigation.

Our results are robust to uncertainties in key parameters (Supplementary Table 4; Supplementary Fig. 2), but need to be interpreted cautiously. Firstly, restored habitats will - 
over a period of one hundred or more years - eventually reach a new equilibrium and net carbon sequestration will decline to zero ${ }^{1,22}$. Actively managing the carbon sink by growing bioenergy crops or by managing forests for fuel-wood or timber might in some circumstances extend the timeframe for mitigation ${ }^{23}$, but might also compromise biodiversity objectives. Secondly, climate change feedbacks might affect our findings by altering soil carbon dynamics and the yields of food crops, livestock, bioenergy crops and trees. However, these effects are likely to be reduced by adaptation measures ${ }^{15,24}$, and provided that non-farmed habitats continue to store much more carbon than farmland we think our conclusions will hold. Thirdly, it is essential to assess the sustainability of yield increases ${ }^{25}$. For example, due regard for animal welfare, local air and water quality and soil function is essential when increasing yields ${ }^{8,25}$. Encouragingly, the techniques we consider that increase yield also have the potential to reduce externalities per unit of production (Supplementary Table 5) and modern livestock breeding techniques allow multiple traits, including health, welfare and productivity, to be considered simultaneously $^{8}$ (see Supplementary Discussion). Last, managing water resources in higher-yielding landscapes will require a focus on improving water use efficiency in crops alongside careful spatial planning of spared land.

Land sparing would have far reaching implications for the UK countryside and would affect landowners, rural communities, ecosystem services and biodiversity. Our projections in Fig. 1 would result in UK forest cover increasing from $12 \%$ to reach $30 \%$ by 2050 - close to that of Germany and France but still less than the European average ${ }^{26}-$ and the restoration of up to 0.7 Mha of wet peatland (Supplementary Table 3). Such large-scale restoration is likely to benefit ecosystem service provision, including water purification, recreation and flood mitigation ${ }^{18,27}$. Land sparing has the potential to be beneficial for biodiversity, including for many species of conservation concern ${ }^{6,27,28}$, but benefits will depend strongly on the use of spared land. In addition, high yield farming involves trade-offs and is likely to be detrimental 
for wild species associated with farmland. Careful implementation - by retaining seminatural pastures of high conservation value, for example - will be important to minimise any detrimental impacts. Growing bioenergy crops on spared land (rather than land needed for food production) addresses concerns over indirect land-use change ${ }^{1}$, but compared with natural habitats might compromise ecosystem services and biodiversity objectives ${ }^{29}$.

Finally, how relevant are our results to other parts of the world? The UK presents a challenging test for the implementation of a land-sparing strategy. Relatively low yield gaps in the $\mathrm{UK}^{30}$ mean that achieving yield increases into the long term will require continued genetic advances. This is compounded by relatively high projected demand growth in the UK driven by a projected population increase of $26 \%$ over the forecast period (Supplementary Table 2). In contrast, in many global regions, yield gaps are quite large ${ }^{30}$ compared with projected growth in agricultural demand ${ }^{5}$ (Supplementary Fig. 3). Clearly the technical and economic feasibility would need to be assessed in each location, but our findings suggest that land sparing may be a promising strategy for reducing greenhouse gas emissions from agriculture and land-use change in several parts of the world besides the UK.

\section{References}

1. IPCC. Climate Change 2014: Mitigation of Climate Change. Contribution of Working Group III to the Fifth Assessment Report of the Intergovernmental Panel on Climate Change. Final Draft. (Cambridge University Press, 2014).

2. MacLeod, M. et al. Developing greenhouse gas marginal abatement cost curves for agricultural emissions from crops and soils in the UK. Agric. Syst. 103, 198-209 (2010).

3. Franks, J. R. \& Hadingham, B. Reducing greenhouse gas emissions from agriculture: Avoiding trivial solutions to a global problem. Land Use Policy 29, 727-736 (2012).

4. Tilman, D., Balzer, C., Hill, J. \& Befort, B. L. Global food demand and the sustainable intensification of agriculture. Proc. Natl. Acad. Sci. 108, 20260-20264 (2011).

5. Alexandratos, N. \& Bruinsma, J. World agriculture towards 2030/2050: the 2012 revision. (FAO, 2012). 
6. Green, R. E., Cornell, S. J., Scharlemann, J. P. W. \& Balmford, A. Farming and the fate of wild nature. Science 307, 550-555 (2005).

7. Climate Change Act 2008. (The Stationery Office, 2008).

8. Thornton, P. K. Livestock production: recent trends, future prospects. Philos. Trans. R. Soc. B Biol. Sci. 365, 2853-2867 (2010).

9. Lobell, D. B. The case of the missing wheat. Environ. Res. Lett. 7, 021002 (2012).

10. Alston, J. M., Beddow, J. M. \& Pardey, P. G. Agricultural Research, Productivity, and Food Prices in the Long Run. Science 325, 1209-1210 (2009).

11. Thirtle, C., Lin Lin, L., Holding, J., Jenkins, L. \& Piesse, J. Explaining the decline in UK agricultural productivity growth. J. Agric. Econ. 55, 343-366 (2004).

12. Murrells, T. et al. UK Greenhouse Gas Inventory, 1990 to 2011: Annual Report for Submission Under the Framework Convention on Climate Change. (DEFRA, 2013).

13. IPCC. 2006 IPCC Guidelines for National Greenhouse Gas Inventories, Prepared by the National Greenhouse Gas Inventories Programme. (IPCC, 2006).

14. Bajželj, B. et al. Importance of food-demand management for climate mitigation. Nat. Clim. Change 4, 924-929 (2014).

15. IPCC. Climate Change 2014: Impacts, Adaptation, and Vulnerability. Contribution of Working Group II to the Fifth Assessment Report of the Intergovernmental Panel on Climate Change. Final Draft. (Cambridge University Press, 2014).

16. McMichael, A. J., Powles, J. W., Butler, C. D. \& Uauy, R. Food, livestock production, energy, climate change, and health. The Lancet 370, 1253-1263 (2007).

17. Thow, A. M., Downs, S. \& Jan, S. A systematic review of the effectiveness of food taxes and subsidies to improve diets: Understanding the recent evidence. Nutr. Rev. 72, 551-565 (2014).

18. Bateman, I. J. et al. Bringing ecosystem services into economic decision-making: Land use in the United Kingdom. Science 341, 45-50 (2013).

19. Cohn, A. S. et al. Cattle ranching intensification in Brazil can reduce global greenhouse gas emissions by sparing land from deforestation. Proc. Natl. Acad. Sci. 201307163 (2014). doi:10.1073/pnas.1307163111

20. Stevenson, J. R., Villoria, N., Byerlee, D., Kelley, T. \& Maredia, M. Green Revolution research saved an estimated 18 to 27 million hectares from being brought into agricultural production. Proc. Natl. Acad. Sci. 110, 8363-8368 (2013). 
21. Nelson, G. C. \& Shively, G. E. Modeling climate change and agriculture: an introduction to the special issue. Agric. Econ. 45, 1-2 (2014).

22. Smith, P. Soils and climate change. Curr. Opin. Environ. Sustain. 4, 539-544 (2012).

23. Read, D. J. et al. Combating Climate Change: A Role for UK Forests. An Assessment of the Potential of the UK's Trees and Woodlands to Mitigate and Adapt to Climate Change. (The Stationery Office, 2009).

24. Fezzi, C., Harwood, A. R., Lovett, A. A. \& Bateman, I. J. The environmental impact of climate change adaptation on land use and water quality. Nat. Clim. Change 5, 255-260 (2015).

25. Godfray, H. C. J. \& Garnett, T. Food security and sustainable intensification. Philos. Trans. R. Soc. B Biol. Sci. 369, 20120273 (2014).

26. FAO. Global Forest Resources Assessment: 2010 Main Report. (FAO, 2010).

27. Balmford, A., Green, R. \& Phalan, B. What conservationists need to know about farming. Proc. R. Soc. B Biol. Sci. 279, 2714-2724 (2012).

28. Phalan, B., Onial, M., Balmford, A. \& Green, R. E. Reconciling food production and biodiversity conservation: Land sharing and land sparing compared. Science 333, 1289-1291 (2011).

29. Rowe, R. L., Street, N. R. \& Taylor, G. Identifying potential environmental impacts of large-scale deployment of dedicated bioenergy crops in the UK. Renew. Sustain. Energy Rev. 13, 271-290 (2009).

30. Mueller, N. D. et al. Closing yield gaps through nutrient and water management. Nature (2012). doi:10.1038/nature11420

Acknowledgements This research was funded by the Cambridge Conservation Initiative Collaborative Fund for Conservation and we thank its major sponsor Arcadia. We thank J. Bruinsma for the provision of demand data, the CEH for the provision of soil data and $\mathrm{J}$. Spencer for invaluable discussions. A.L. was supported by a Gates Cambridge Scholarship.

Author contributions A.B., A.L. and R.G. conceived the study. A.L. conducted the analysis and prepared the manuscript. A.H., D.K., E.W., K.G., P.C., P.S. and R.F supplied data. All authors contributed in the writing and editing of the manuscript.

Competing financial interests The authors declare no competing financial interests. 
Corresponding author Correspondence and requests for materials should be addressed to A.L. (aj185@ cam.ac.uk). 
Table 1: Scenarios of yield and feed conversion ratio

\begin{tabular}{|c|c|c|c|c|c|}
\hline \multirow[b]{2}{*}{ Commodity } & \multicolumn{3}{|c|}{ Yield $\left(\mathrm{t} \mathrm{ha}^{-1} \mathrm{yr}^{-1}\right)$ or FCR $\left(\mathrm{MJ} \mathrm{kg}^{-1}\right)$} & \multicolumn{2}{|c|}{$\begin{array}{c}\text { Average rate of } \\
\text { change } 2010-2050 \\
\left(\% \mathrm{yr}^{-1}\right)\end{array}$} \\
\hline & 2010 & $\begin{array}{l}2050 \\
\text { Lower- } \\
\text { bound }\end{array}$ & $\begin{array}{l}2050 \\
\text { Upper- } \\
\text { bound }\end{array}$ & $\begin{array}{l}\text { Lower- } \\
\text { bound }\end{array}$ & $\begin{array}{l}\text { Upper- } \\
\text { bound }^{\dagger}\end{array}$ \\
\hline Cereals & 7.0 & 6.5 & 13.0 & $-0.2 \%$ & $1.6 \%$ \\
\hline Oilseeds & 3.5 & 3.5 & 6.8 & $0.0 \%$ & $1.7 \%$ \\
\hline Potatoes & 43.7 & 43.7 & 74.0 & $0.0 \%$ & $1.3 \%$ \\
\hline Sugar beet & 68.0 & 68.0 & 113.0 & $0.0 \%$ & $1.3 \%$ \\
\hline Fruit and vegetables & 20.0 & 20.0 & 30.0 & $0.0 \%$ & $1.0 \%$ \\
\hline Forage maize & 8.1 & 7.1 & 10.7 & $-0.3 \%$ & $0.7 \%$ \\
\hline Forage legumes & 3.7 & 3.7 & 6.0 & $0.0 \%$ & $1.2 \%$ \\
\hline Other forage crops & 7.6 & 7.6 & 12.3 & $0.0 \%$ & $1.2 \%$ \\
\hline Temporary grass* & 1.0 & 1.0 & 1.8 & $0.0 \%$ & $1.5 \%$ \\
\hline Permanent grass ${ }^{*}$ & 1.0 & 1.0 & 1.8 & $0.0 \%$ & $1.5 \%$ \\
\hline Rough grazing ${ }^{*}$ & 1.0 & 1.0 & 1.0 & $0.0 \%$ & $0.0 \%$ \\
\hline Beef meat & 147 & 147 & 98 & $0.0 \%$ & $-1.0 \%$ \\
\hline Milk & 11 & 11 & 7 & $0.0 \%$ & $-1.0 \%$ \\
\hline Pig meat & 38 & 38 & 25 & $0.0 \%$ & $-1.0 \%$ \\
\hline Sheep meat & 214 & 214 & 161 & $0.0 \%$ & $-0.7 \%$ \\
\hline Poultry meat & 33 & 33 & 24 & $0.0 \%$ & $-0.8 \%$ \\
\hline Eggs & 31 & 31 & 23 & $0.0 \%$ & $-0.8 \%$ \\
\hline
\end{tabular}

Crop yields and livestock feed conversion ratios (FCRs) in 2010 and lower- and upper-bound assumptions in 2050. FCRs apply to animals producing meat, milk or eggs, not the entire herd; a negative change indicates improving feed conversion efficiency. *For modelling purposes, grassland yields are expressed relative to the 2010 yield which was set to a value of 1. ${ }^{\dagger}$ Mean upper-bound yield growth of $1.3 \% \mathrm{yr}^{-1}$ reported in the text is the average of the figures shown (with FCR growth expressed as a positive quantity), weighted by the energy content of production of each commodity in 2010 . 


\section{Figure legends}

\section{Figure 1. Mitigation of greenhouse gas emissions from agriculture by land sparing.}

a. Net greenhouse gas (GHG) emissions in 2050 are shown as the sum of emissions from farming and emissions from land-use change (which may be positive or negative). Yields of all commodities in 2050 are scaled linearly between the lower- and upper-bounds shown in Table 1. Emissions representing an $80 \%$ reduction relative to baseline net emissions in 1990, and equivalent net emissions in 2010, are shown for reference (20.1 $\mathrm{Mt} \mathrm{CO}_{2} \mathrm{e} \mathrm{yr}^{-1}$ and 73.9 Mt $\mathrm{CO}_{2} \mathrm{e} \mathrm{yr}^{-1}$ respectively, see Supplementary Table 1). b. Contribution of crop yield and livestock feeding efficiency gains to projected upper-bound mitigation in 2050. Projected net emissions in 2050 with yields, FCRs and ruminant diets at 2010 levels (left-hand bar; see Table 1); the effect of upper-bound assumptions (Table 1) on emissions from farming and land-use change emissions (intermediate bars); and the cumulative effect of all changes, giving projected net emissions in 2050 under upper-bound yield assumptions (right-hand bar). 


\section{Figure 2: Greenhouse gas mitigation by coupling land sparing with demand}

management. a. Reduction in the consumption of animal products. Shading and contours indicate net greenhouse gas (GHG) emissions in 2050 as a function of the per capita reduction in calories from animal products by 2050 relative to 2010 (vertical axis; see Supplementary Methods) and yields in 2050 (horizontal axis; scaled linearly between the lower- and upper-bounds shown in Table 1). Emissions representing an $80 \%$ reduction

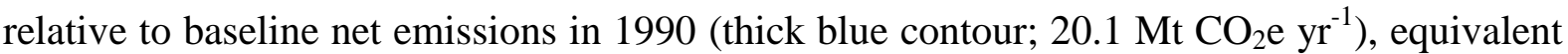
net emissions in 2010 (thick black contour; 73.9 $\mathrm{Mt} \mathrm{CO}_{2} \mathrm{e} \mathrm{yr}^{-1}$ ) and zero net emissions (thick orange contour) are also shown for reference. The enclosed dashed region indicates the mitigation potential of coupling moderate reductions in meat consumption with moderate yield increases under land sparing. b. Reduction in food waste. As for (a) but the vertical axis represents the per capita reduction in post-harvest food waste by 2050 relative to 2010 (see Supplementary Methods). 
Figure 3: Upper-bound mitigation potential in 2050 under different uses of spared land.

Results assume upper-bound yield increases and different uses of spared land: natural regeneration; broadleaved woodland (the main scenario presented in Fig. 1); coniferous woodland; and bioenergy crops. Miscanthus and short-rotation coppice (SRC) are shown assuming three different fossil fuel displacement pathways: coal, the current UK electricity grid average, and natural gas. The nature of mitigation is different depending on the use of spared land. Mitigation under natural regeneration and forestry is primarily due to carbon sequestered in the soils and biomass of restored habitats and would normally be reported in the 'Land use, land-use change and forestry' sector. For bioenergy crops, the mitigation arises primarily due to avoided emissions from displaced fossil fuels, and would normally be reported in the energy sector. 